Ciência Florestal, Santa Maria, v. 23, n. 1, p. 55-66, jan.-mar., 2013

ISSN 0103-9954

\title{
NUTRIÇÃO E CRESCIMENTO DA ERVA-MATE SUBMETIDA À CALAGEM
}

\author{
GROWTH AND NUTRITION OF MATE TEA SUBMITTED TO LIMING
}

\author{
Delmar Santin ${ }^{1}$ Eliziane Luiza Benedetti ${ }^{2}$ Jéssica Fernandes Kaseker ${ }^{3}$ Marília Camotti Bastos ${ }^{4}$ \\ Carlos Bruno Reissmann ${ }^{5}$ Ivar Wendling ${ }^{6}$ Nairam Félix de Barros ${ }^{7}$
}

\begin{abstract}
RESUMO
A erva-mate ocorre naturalmente em solos ácidos, mas é comumente cultivada em consórcio com culturas anuais que requerem correção da acidez. Contudo, pouco se conhece sobre seu comportamento frente à calagem. O objetivo desse estudo foi verificar a influência do calcário no crescimento e estado nutricional de plantas jovens de erva-mate. Para isso, incubou-se o solo com $0,0,0,7,1,8,2,5,3,4,4,3$ e 5,2 $\mathrm{g} \mathrm{dm}^{-3}$ de calcário. Após 21 dias de incubação, mudas de erva-mate foram transplantadas para vasos com $3 \mathrm{dm}^{3}$ de solo. Após 210 dias determinou-se o crescimento em altura e diâmetro, posteriormente separou-se as plantas em folha, caule e raiz para determinação da área foliar, comprimento e volume de raízes, produção de matéria seca e teor de $\mathrm{N}, \mathrm{P}, \mathrm{K}, \mathrm{Ca}, \mathrm{Mg}, \mathrm{Fe}, \mathrm{Cu}, \mathrm{Zn}, \mathrm{Mn}$ e Al, além da eficiência de utilização de $\mathrm{Ca}$ e $\mathrm{Mg}$ pela planta. O solo foi analisado quimicamente. O calcário elevou os teores de $\mathrm{Ca}, \mathrm{Mg}$ e $\mathrm{K}$ do solo e estimulou um pequeno aumento no crescimento da parte aérea das plantas, o que não ocorreu para o sistema radicular. O máximo crescimento e produção de matéria seca da parte aérea da erva-mate ocorreu em pequenas doses de calcário, quando o teor de $\mathrm{Ca}$ e $\mathrm{Mg}$ no solo se situava, respectivamente, na faixa de 3,3 a 3,4 e 1,1 a 1,4 $\mathrm{cmol}_{\mathrm{c}} \mathrm{dm}^{-3}$. Nas maiores doses de calcário os teores foliares de $\mathrm{Cu}, \mathrm{Zn}, \mathrm{Mn}$ e Fe e o crescimento das plantas foram fortemente reduzidos. A eficiência de utilização de $\mathrm{Ca}$ e $\mathrm{Mg}$ pela planta reduziu com o aumento da disponibilidade dos mesmos no solo. A erva-mate mostrou ser pouco responsiva à calagem e muito tolerante ao Al. Desta forma, a aplicação de calcário deve visar o suprimento de $\mathrm{Ca}$ e $\mathrm{Mg}$ para as plantas e não a correção da acidez do solo no intuito de neutralizar o Al trocável.
\end{abstract}

Palavras-chave: calcário; Ilex paraguariensis; nutrição mineral.

\section{ABSTRACT}

Mate tea trees are native of south Brazil, growing on acid soils. However, small farmers intercrop this species with agricultural crops, which usually require liming to reduce the soil acidity. Therefore, this study aimed to verify the liming effect on Mate tea seedling growth and nutritional status. Samples of an acidic soil $\left(\mathrm{pH}=4.2, \mathrm{Al}^{3+}=3.9 \mathrm{cmol}_{\mathrm{c}} \mathrm{dm}^{-3}\right)$ were incubated with increased rates $(0.0,0.7,1.8,2.5,3.4,4.3$ and $5.2 \mathrm{~g} \mathrm{dm}^{-3}$ ) of a liming material for 21 days. Then mate tea seedlings were transplanted to the pots containing $3 \mathrm{dm}^{3}$ of soil, grown for 210 days. At the end of this period, seedlings were harvested, split into leaf plants,

1. Engenheiro Florestal, Dr., Pós-doutorando do Programa de Pós-Graduação em Ciência do Solo da Universidade do Estado de Santa Catarina. Av. Luiz de Camões, CEP 88520-000, Lages (SC). Bolsista CNPq. desantinflorestal@yahoo.com.br

2. Engenheira Agrônoma, Dra., Professora do Instituto Federal de Santa Catarina, Campus Canoinhas, Av. Expedicionários, Bairro Campo da Água Verde, CEP 89460-000, Canoinhas (SC). elibettiagro@yahoo.com.br

3. Engenheira Agrônoma, Msc., Doutoranda do Programa de Pós-Graduação em Ciência do Solo, Universidade do Estado de Santa Catarina, Av. Luiz de Camões, CEP 88520-000, Lages (SC). jessikaseker@hotmail.com

4. Engenheira Agrônoma, Mestranda do Programa de Pós-Graduação em Ciências do Solo, Setor de Ciências Agrárias, Universidade Federal do Paraná, Rua dos Funcionários, 1540, CEP 80035-050, Curitiba (PR). mcamotti@hotmail.com

5. Engenheiro Florestal, Dr., Professor Sênior do Programa de Pós-Graduação em Ciências do Solo, Universidade Federal do Paraná, Rua dos Funcionários, 1540, CEP 80035-050, Curitiba (PR). reissman@ufpr.br

6. Engenheiro Florestal, Dr., Pesquisador da Embrapa Florestas, Estrada da Ribeira Km 111, CEP 83411-000, Colombo (PR). ivar@enpf.embrapa.br

7. Engenheiro Florestal, Dr., Professor do Departamento de Solos, Universidade Federal de Viçosa. Av. PH Rolfs, Campus Universitário, CEP 36570-000, Viçosa (MG).nfbarros@ufv.br

Recebido para publicação em 23/12/2009 e aceito em 8/11/2011

Ci. Fl., v. 23, n. 1, jan.-mar., 2013 
stem, and roots for determining the foliar area, root length and volume, dry matter production and levels of $\mathrm{N}, \mathrm{P}, \mathrm{K}, \mathrm{Ca}, \mathrm{Mg}, \mathrm{Fe}, \mathrm{Cu}, \mathrm{Zn}, \mathrm{Mn}$ and $\mathrm{Al}$ as well as the efficiency of the usage of $\mathrm{Ca}$ and $\mathrm{Mg}$ by the plant. The soil was analyzed chemically. Calcareous elevated the values of $\mathrm{Ca}, \mathrm{Mg}$ and $\mathrm{K}$ in the soil and stimulated a little increase in the aerial parts of the plants. Seedling maximum dry matter production was obtained at low rates of liming and drastically decreased at high liming rates. Micronutrients and Al seedling decreased with lime rate. Calcium and Mg utilization efficiency reduced with increasing availability of these nutrients in the soil. It can be concluded that mate tea plants are tolerant to soil acidity and the lime is needed only to supply $\mathrm{Ca}$ and $\mathrm{Mg}$ nutritional requirements.

Keywords: lime, Ilex paraguariensis, mineral nutrition.

\section{INTRODUÇÃO}

A calagem, além de corrigir a acidez do solo, supre em $\mathrm{Ca}$ e $\mathrm{Mg}$ às plantas (BISSANI et al., 2004), sendo que esses elementos participam de importantes funções fisiológicas. $\mathrm{O} \mathrm{Ca}$ se destaca como componente da parede celular e o $\mathrm{Mg}$ participa como ativador enzimático e constituinte da molécula de clorofila (MENGEL e KIRKBY, 1987; MARSCHNER, 1995). Porém, espécies que se desenvolvem naturalmente em solos ácidos, como a erva-mate, podem não responder à calagem (GAIAD, 2003), como observado por Reissmann et al. (1991). Por outro lado, em condições de baixos teores de $\mathrm{Ca}$ e Mg no solo, pequenas doses de calcário podem suprir esses elementos às plantas.

A erva-mate é uma das culturas de maior importância em sistemas agroflorestais no sul do Brasil, sendo explorada na forma natural, consorciada com outras espécies florestais ou intercalada com culturas anuais (DEDECEK e RODIGHERI, 1999). Essas culturas, em geral, requerem correção da acidez do solo para que se obtenham elevadas produtividades e, nessas condições, a erva-mate cresceria em solos com $\mathrm{pH}$ acima do que é por ela requerido. A questão que se apresenta é se essas condições poderiam prejudicar o crescimento da erva-mate. Diante do exposto, o objetivo desse estudo foi verificar a influência de doses de calcário no crescimento e estado nutricional de plantas jovens de erva-mate.

\section{MATERIAL E MÉTODOS}

O experimento foi instalado em agosto de 2006 em casa de vegetação no Departamento de Solos da Universidade Federal do Paraná (UFPR) - Curitiba. Foram utilizadas mudas produzidas por miniestaquia a partir de propágulos de plantas juvenis de erva-mate, de duas matrizes (F6 e F7) provenientes, respectivamente, dos municípios de
Bituruna e Rebouças, PR. Após cinco meses de idade, quando atingiram, aproximadamente $9 \mathrm{~cm}$ de altura, as mudas foram transferidas para vasos e submetidas aos tratamentos. A unidade experimental foi constituída por um vaso de polietileno rígido com capacidade de $3,5 \mathrm{dm}^{3}$ com duas mudas de erva-mate. $\mathrm{O}$ experimento foi conduzido em blocos casualizados com quatro repetições.

O substrato utilizado foi $3 \mathrm{dm}^{3}$ vaso $^{-1}$ de Latossolo Vermelho distrófico, coletado na profundidade de 5 a $25 \mathrm{~cm}$, em São Mateus do Sul - PR, tendo como principais propriedades: $\mathrm{pH}\left(\mathrm{CaCl}_{2}\right)$ de 4,2; $\mathrm{Ca}^{2+}, \mathrm{Mg}^{2+}, \mathrm{Al}^{3+}, \mathrm{H}+\mathrm{Al}, \mathrm{CTC}_{\mathrm{pH} 7,0} \mathrm{e}$ soma de bases (SB), respectivamente, de $0,3,0,1$, $3,9,12,1,12,6$ e $0,52 \mathrm{cmol}_{\mathrm{c}} \mathrm{dm}^{-3}$; saturação por bases (V), saturação por $\mathrm{Al}(\mathrm{m})$, teor de $\mathrm{MO}$ e de argila, respectivamente, de 4,0, 88,0,6,0 e $82,5 \%$ e disponibilidade de $\mathrm{P}$ e $\mathrm{K}$, respectivamente, de 1,9 e $46,9 \mathrm{mg} \mathrm{dm}^{-3}$.

As doses de calcário (Tabela 1) foram calculadas para se atingir $0,15,30,45,60,75$ e $90 \%$ de saturação por bases (V \%). O solo, com a dose de calcário correspondente a cada tratamento, foi incubado por 21 dias, com umidade correspondente a $65 \%$ da capacidade de campo. Após este período transferiram-se duas mudas de erva-mate para cada vaso, tendo a umidade do solo mantida com adição de água desionizada conforme necessidade das plantas. O calcário dolomítico, tipo filler apresentava PRNT de $104 \%$ e teores de $\mathrm{CaO}$ e $\mathrm{MgO}$, respectivamente, de 323 e $216 \mathrm{~g} \mathrm{~kg}^{-1}$ de calcário. Todos os tratamentos receberam a mesma adubação corretiva de N, P e K para a cultura da erva-mate (plantio) (SBCS, 2004), considerando 2.000 plantas $\mathrm{ha}^{-1}$, sendo as fontes, respectivamente, ureia, superfosfato triplo e cloreto de potássio (Tabela 1).

Após 210 dias da instalação do experimento determinou-se: altura (HT), diâmetro do colo (DC), área foliar (AF), volume radicular (VR) e comprimento radicular (CR); assim como, matéria seca da folha (MSF), do caule (MSC), de raiz (MSR) 
TABELA 1: Doses de calcário e de N, P e K utilizadas no cultivo de plantas jovens de erva-mate (Ilex paraguariensis A. St.-Hil.).

TABLE 1: $\quad$ Rates of lime and N, P and K used to grow mate tea (Ilex paraguariensis A. St.-Hil.) seedlings.

\begin{tabular}{|c|c|c|c|c|c|c|}
\hline \multirow{3}{*}{ Tratamento } & \multirow{2}{*}{\multicolumn{2}{|c|}{ Dose de calcário }} & & \multicolumn{3}{|c|}{ Adubação corretiva } \\
\hline & & & & $\mathrm{N}$ & $\mathrm{P}_{2} \mathrm{O}_{5}$ & $\mathrm{~K}_{2} \mathrm{O}$ \\
\hline & $\mathrm{g} \mathrm{dm}^{-3}$ & $\mathrm{~g} \mathrm{vaso}^{-1}$ & t ha- ${ }^{-1}$ & \multicolumn{3}{|c|}{ - - - - mg dm $\mathrm{m}^{-3} \ldots$} \\
\hline $\mathrm{T} 1$ & 0,00 & 0,00 & 0,00 & 150 & 250 & 200 \\
\hline $\mathrm{T} 2$ & 0,67 & 2,00 & 1,33 & 150 & 250 & 200 \\
\hline $\mathrm{T} 3$ & 1,75 & 5,25 & 3,50 & 150 & 250 & 200 \\
\hline $\mathrm{T} 4$ & 2,48 & 7,45 & 4,97 & 150 & 250 & 200 \\
\hline T5 & 3,39 & 10,18 & 6,78 & 150 & 250 & 200 \\
\hline T6 & 4,30 & 12,90 & 8,60 & 150 & 250 & 200 \\
\hline $\mathrm{T} 7$ & 5,25 & 15,74 & 10,49 & 150 & 250 & 200 \\
\hline
\end{tabular}

e total (MST) de cada planta; $\mathrm{pH}$, teor de $\mathrm{Al}^{3+}, \mathrm{H}+\mathrm{Al}$, $\mathrm{Ca}^{2+}, \mathrm{Mg}^{2+}$ e disponibilidade de $\mathrm{K}$ e P no solo; e teor de $\mathrm{N}, \mathrm{P}, \mathrm{K}, \mathrm{Ca}, \mathrm{Mg}, \mathrm{Fe}, \mathrm{Mn}, \mathrm{Cu}, \mathrm{Zn}$ e Al na matéria vegetal.

A HT foi medida com régua $(\mathrm{cm})$ do nível do solo ao ápice das plantas e o DC, medido com paquímetro (mm) a $0,5 \mathrm{~cm}$ do solo. A AF, VR e CR das raízes foram obtidos através de scanner acoplado ao software Whinrhizo, marca LA 1600, versão 982003. Para determinação da matéria seca, o material vegetal foi separado em folha, caule e raiz, lavados, secos em estufa a $65^{\circ} \mathrm{C}$ e pesados, posteriormente foram moídos em partículas menores que $0,50 \mathrm{~mm}$ para análise química.

No solo, após o cultivo, determinouse o $\mathrm{pH}\left(\mathrm{CaCl}_{2}\right), \mathrm{Al}^{3+}, \mathrm{H}+\mathrm{Al}, \mathrm{Ca}^{2+}$ e $^{\mathrm{Mg}^{2+}}$ e a disponibilidade de $\mathrm{K}$ e $\mathrm{P}$ conforme metodologia descrita por Embrapa (1997). A partir desses dados calculou-se a soma de bases (SB), CTC $_{\text {efetiva }}$ e saturação por bases (V \%). A SB foi calculada pela soma de cátions de reação básica $\left(\mathrm{Ca}^{2+}+\mathrm{Mg}^{2+}\right.$ $+\mathrm{K}^{+}$) em $\mathrm{cmol}_{\mathrm{c}} \mathrm{dm}^{-3}$ e, a $\mathrm{CTC}_{\text {efetiva, }}$ pela SB mais o cátion $\mathrm{Al}^{3+} \mathrm{em} \mathrm{cmol}_{\mathrm{c}} \mathrm{dm}^{-3}$. A V \% calculou-se a partir da fórmula: $V \%=(S B \times 100) \div C T C_{\mathrm{pH} 7,0}$, sendo a $\mathrm{CTC}_{\mathrm{pH} 7,0}=$ soma de cátions de reação básica $\left(\mathrm{Ca}^{2+}\right.$ $\left.+\mathrm{Mg}^{2+}+\mathrm{K}^{+}\right)$mais o de reação ácida $\left(\mathrm{H}^{+}+\mathrm{Al}^{3+}\right) \mathrm{em}$ $\mathrm{cmol}_{\mathrm{c}} \mathrm{dm}^{-3}$ (SBCS, 2004).

No material vegetal a extração de $\mathrm{P}, \mathrm{K}, \mathrm{Ca}$, $\mathrm{Mg}, \mathrm{Fe}, \mathrm{Mn}, \mathrm{Cu}, \mathrm{Zn}$ e Al foi realizada com incineração em mufla a $500^{\circ} \mathrm{C}$ e solubilização da cinza por $\mathrm{HCl}$ $3 \mathrm{~mol} \mathrm{~L}^{-1}$. A determinação do $\mathrm{P}$ foi realizada por colorimetria com vanadato-molibdato de amônio e leitura em espectrofotômetro UV/VIS; o K por fotometria de emissão de chama e o $\mathrm{Ca}, \mathrm{Mg}, \mathrm{Fe}$, $\mathrm{Mn}, \mathrm{Cu}, \mathrm{Zn}$ e Al por espectrofotometria de absorção atômica (MARTINS e REISSMANN, 2007). O N foi extraído por digestão sulfúrica, destilação do extrato com hidróxido de sódio, recebido o destilado com ácido bórico e titulação com ácido clorídrico 0,1 $\mathrm{mol} \mathrm{L}^{-1}$ (BREMNER, 1996).

A distribuição relativa dos nutrientes nos compartimentos da planta foi obtida na dose mais próxima da dose média de máxima eficiência técnica para altura, diâmetro do colo, matéria seca da folha e do caule.

A eficiência de utilização dos nutrientes (EUN), para Ca e $\mathrm{Mg}$, foi calculada pela razão entre matéria seca da planta e o conteúdo de nutrientes acumulados (gMS g-1) (BARROS et al., 1986).

Todas as variáveis foram submetidas à análise de variância. Posteriormente, as variáveis de solo, variáveis de crescimento da plantas, teores de elementos na planta e a EUN foram submetidas à regressão e, as médias do conteúdo de nutrientes foram comparadas pelo teste de Tukey. Todas as análises foram efetuadas a $5 \%$ de probabilidade ( $\mathrm{p}<0,05)$ usando-se o software SISVAR (FERREIRA, 2008).

\section{RESULTADOS E DISCUSSÃO}

\section{Solo}

De maneira geral, a aplicação de calcário melhorou as propriedades químicas do solo, elevando a disponibilidade dos nutrientes às plantas. $\mathrm{O}$ calcário aumentou a soma (SB), saturação por bases (V) e 
$\mathrm{CTC}_{\text {efetiva }}$, as quais estão diretamente relacionadas com o aumento do teor de $\mathrm{Ca}^{2+}, \mathrm{Mg}^{2+}$ e $\mathrm{K}$ e, com a redução do Al trocável no solo (Figura 1A, B, C e D). Apesar das doses de calcário terem elevado o $\mathrm{pH}$ do solo o $\mathrm{Al}^{3+}$ não foi totalmente neutralizado (Figura 1A). Isso se deve às características do solo, em especial aos altos teores de MO e de argila, que elevam o poder tampão do solo (BISSANI et al., 2004), dificultando a neutralização do $\mathrm{Al}^{3+}$.

A redução do teor de $\mathrm{Al}$ trocável, que alcançou valores próximo de zero na maior dose de calcário é consequência direta do aumento do $\mathrm{pH}$ do solo, causado pela adição do corretivo (Figura 1A). Isso se deve a diminuição da atividade total do $\mathrm{Al}$ em solução à medida que $\mathrm{o} \mathrm{pH}$ aumenta, atingindo valores mínimos na faixa de $\mathrm{pH}$ de 5,5 a 8,0 (LINDSAY, 2001; MELLO e PEREZ, 2009).
A melhoria das propriedades químicas do solo não foi consequência apenas da aplicação do calcário, mas também da adução corretiva de N, P e $\mathrm{K}$. Isso é verificado principalmente pelo aumento do teor de $\mathrm{Ca}$ e $\mathrm{K}$ na testemunha (Figura 1B e C), em comparação ao teor desses elementos no solo antes da incubação. Porém, o aumento significativo do $\mathrm{Ca}$ e do $\mathrm{K}$ em função das doses (Figuras $1 \mathrm{~B}$ e C), se deve exclusivamente à ação do calcário, visto que todos os tratamentos receberam a mesma adubação corretiva (Tabela 1).

A influência significativa do calcário para a disponibilidade de $\mathrm{K}$ no solo (Figura $1 \mathrm{C}$ ) e não significativa para a do $\mathrm{P}$ (Figura 1D), provavelmente esteja relacionada à forma diferenciada de energia de ligação em que cada elemento é retido na superfície das partículas do solo, sendo que, para

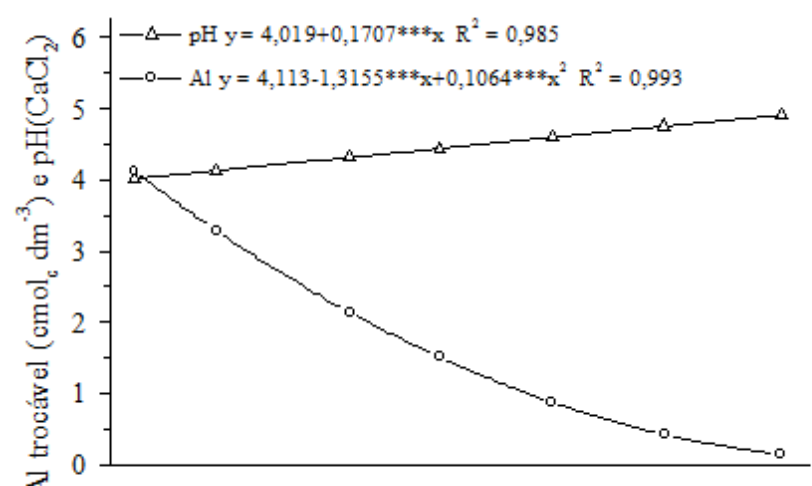

(A)

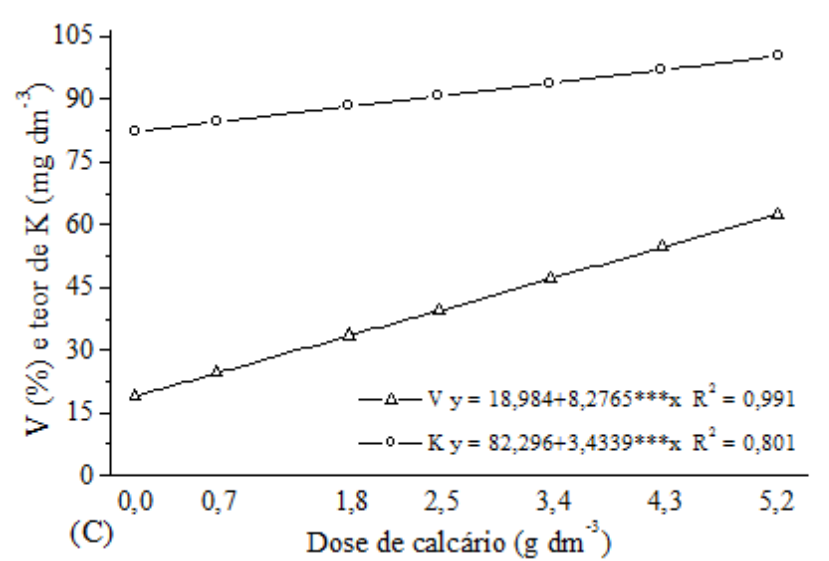

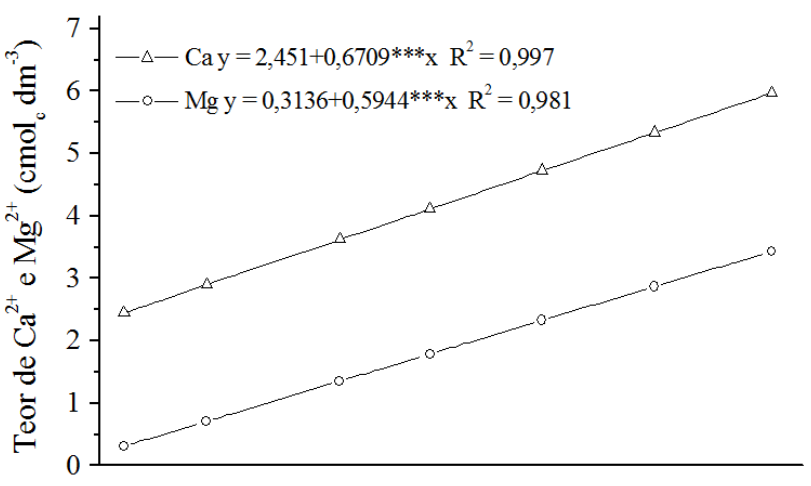

(B)

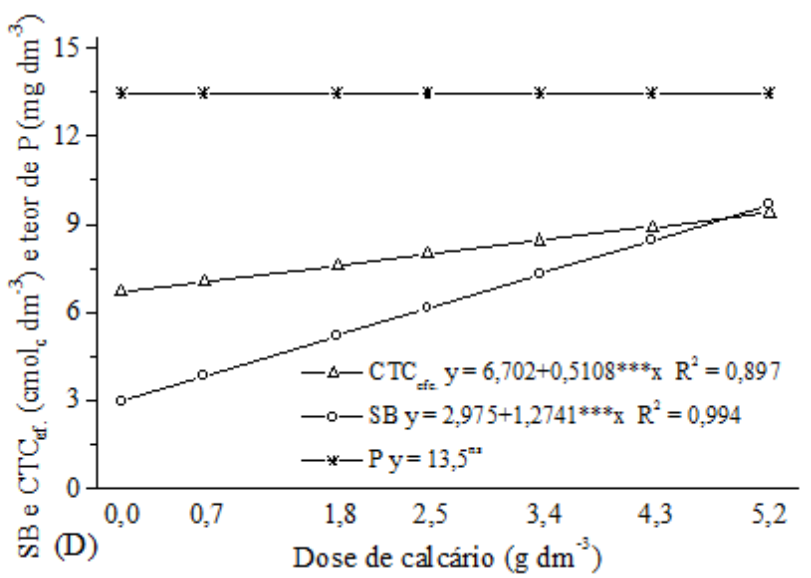

FIGURA 1: Valores de $\mathrm{pH}$ e teor de $\mathrm{Al}^{3+}(\mathrm{A})$; teor de $\mathrm{Ca}^{2+}$ e $\mathrm{Mg}^{2+}(\mathrm{B})$; teor de $\mathrm{K}$ e saturação por bases (V) (C) e $\mathrm{CTC}_{\text {eftiva }}$, soma de bases (SB) e teor de P (D) do solo cultivado com plantas jovens de erva-mate (Ilex paraguariensis A. St.-Hil.) submetidas à doses de calcário. ${ }^{\text {ns }} \mathrm{e}{ }^{* * *}$ não significativo e significativo a $0,1 \%$, respectivamente.

FIGURE 1: $\mathrm{pH}$ values and $\mathrm{Al}^{3+}$ content (A), $\mathrm{Ca}^{2+}$ and $\mathrm{Mg}^{2+}$ content (B), $\mathrm{K}$ content and $\mathrm{V}$ value (C) and effective CEC and sum of bases and $\mathrm{P}$ content (D) of the soil used for mate tea (Ilex paraguariensis A. St.-Hil.) seedlings growth as affected by lime rates. ${ }^{\text {ns }}$ and $* * *$ non significant and significant to $0,1 \%$, respectively. 
o $\mathrm{K}$ predomina ligação eletrostática e para o $\mathrm{P}$ a quimiossorção ou adsorção específica (MEURER et al, 2004). Em solos ácidos, apesar do aumento do $\mathrm{pH}$ melhorar a disponibilidade de $\mathrm{K}$ e $\mathrm{P}$, a alta afinidade do $\mathrm{P}$ com óxidos e hidróxidos de Fe e Al (MELLO e PEREZ, 2009) pode ter limitado o aumento de seu teor pela pequena elevação do $\mathrm{pH}$ verificado. Apesar de a dose máxima de calcário ter elevado apenas 0,9 unidades de $\mathrm{pH}$, o teor de $\mathrm{Ca}^{2+}$ e $\mathrm{Mg}^{2+}$ no solo passaram de 2,5 e $0,3 \mathrm{cmol}_{\mathrm{c}} \mathrm{dm}^{-3}$, respectivamente, para 5,9 e 3,4 $\mathrm{cmol}_{\mathrm{c}} \mathrm{dm}^{-3}$ (Figura 1B), passando respectivamente, do nível médio e baixo para alto (SBCS, 2004).

\section{Planta}

O crescimento da erva-mate foi influenciado pelos tratamentos. Porém, para a maioria das variáveis, a dose de máxima eficiência técnica (MET) ocorreu em pequenas doses de calcário (Figura 2A, B, C e D).

Para a altura, diâmetro do colo (DC) e área foliar (AF) a dose de MET foi, respectivamente, de 1,9, 1,7 e 1,9 $\mathrm{g} \mathrm{dm}^{-3}$ de calcário (Figuras $2 \mathrm{~A} \mathrm{e} \mathrm{B).} \mathrm{A}$ máxima produção de matéria seca da folha (MSF), do caule (MSC), da raiz (MSR) e total (MST) ocorreu, respectivamente, nas doses de 1,3, 1,5, 0,0 e $1,2 \mathrm{~g} \mathrm{dm}^{-3}$ de calcário (Figura 2C). Verifica-se que a magnitude da resposta da erva-mate ao calcário é pouco expressiva, sendo positiva apenas em doses relativamente baixas. Isso caracteriza a ervamate como tolerante a acidez do solo e de média exigência em Ca e Mg. De acordo com Furtini Neto et al. (1999a) espécies florestais nativas podem ou não responder à calagem e, consequentemente,
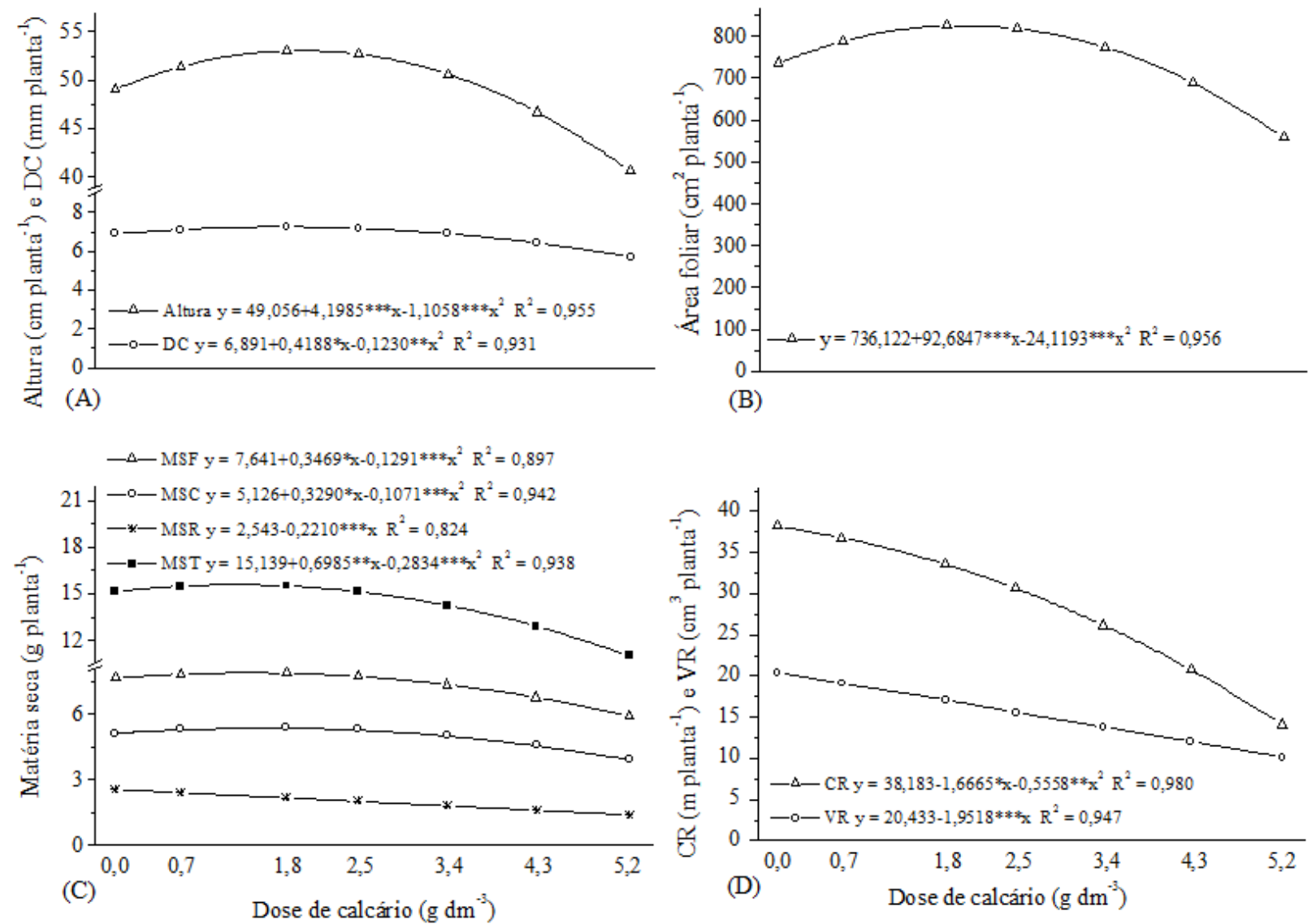

FIGURA 2: Altura e diâmetro basal do caule (DC) (A); área foliar (B); matéria seca da folha (MSF), da raiz (MSR), do caule (MSC) e total (MST) (C); comprimento radicular (CR) e volume de raízes (VR) (D) de plantas jovens de erva-mate (Ilex paraguariensis A.St.-Hil.) submetidas a doses de calcário. ${ }^{*}, * *$ e $* * *$ significativo a 5,1 e $0,1 \%$, respectivamente.

FIGURE 2: Mate seedling height and diameter (DC) (A); leaf foliar (B); leaf (MSF), root (MSR), stem (MSC) e total (MST) dry weight (C); root growth (CR) and root volume (VR) (D) of mate seedlings (Ilex paraguariensis A. St.-Hil.) as affected by lime rates. *,** and *** significant at 5,1 and $0,1 \%$, respectively. 
apresentar comportamento diferente em relação à acidez do solo, saturação por bases e por Al.

Resultados positivos à calagem foram obtidos por Benedetti et al. (2009) com plantas jovens de espinheira-santa (Maytenus ilicifolia) e por Furtini Neto et al. (1999b) com mudas de cedro (Cedrela fissilis), espécies com a mesma ocorrência geográfica da erva-mate. Já para a erva-mate, a calagem teve efeito negativo em mudas (REISSMANN et al., 1991) e em plantios a campo (REISSMANN et al., 1997), indicando que efeitos positivos só ocorrem em condições de solo com teores em nível baixo em $\mathrm{Ca}$ e $\mathrm{Mg}$, sendo o suprimento desses nutrientes o principal objetivo da calagem para essa espécie.

O pequeno aumento na produção de MSF, MSC e MST (Figura 2C) foi verificado quando

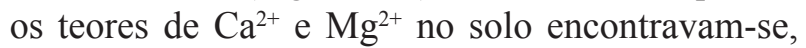
respectivamente, entre 3,3 a 3,5 e 1,0 a 1,2 $\mathrm{cmol}_{c} \mathrm{dm}^{-3}$ (Figura 1B) e de $\mathrm{Al}$ entre 2,4 a 2,7 $\mathrm{cmol}_{\mathrm{c}} \mathrm{dm}^{-3}$ (Figura 1A). A dose de MET para a MST foi de $1,2 \mathrm{~g} \mathrm{dm}^{-3} \mathrm{de}$ calcário, correspondendo a 3,3 e $1,0 \mathrm{cmol}_{\mathrm{c}} \mathrm{dm}^{-3}$, respectivamente, de $\mathrm{Ca}^{2+}$ e de $\mathrm{Mg}^{2+}$ no solo (Figura 2C). A baixa e/ou ausência de resposta da erva-mate à calagem fez com que Reissmann et al. (1997) e Reissmann e Carneiro (2004) a considerassem como uma espécie calcífuga. Os resultados deste trabalho também confirmam esta hipótese, pois, segundo Mengel e Kirkby (1987) e Marschner (1995), uma das principais características de espécies calcífugas é a tolerância a altos teores de Al no solo. No entanto, o teor de $\mathrm{Ca}^{2+}$ e $\mathrm{Mg}^{2+}$ no solo (3,3 e 1,0 $\mathrm{cmol}_{\mathrm{c}} \mathrm{dm}^{-3}$, respectivamente) é considerado nível médio (SBCS, 2004), suficientes para o bom desenvolvimento da maioria das culturas agrícolas. Isso nos mostra a possibilidade de cultivo da erva-mate consorciada com culturas agrícolas menos exigentes em calagem, desde que as doses de calcário sejam aplicadas com cautela.

As doses de calcário influenciaram negativamente o comprimento (CR) e o volume (VR) radicular. Isso é comprovado pela dose de MET para o CR já em $1,5 \mathrm{~g} \mathrm{dm}^{-3}$ de calcário e decréscimo linear do VR com o aumento das doses (Figura

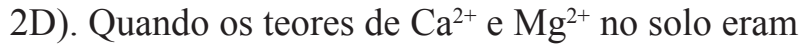
respectivamente de $3,4 \mathrm{e} 1,2 \mathrm{cmol}_{\mathrm{c}} \mathrm{dm}^{-3}\left(1,5 \mathrm{~g} \mathrm{dm}^{-3} \mathrm{de}\right.$ calcário) o CR foi de $34,4 \mathrm{~m}$ planta $^{-1}$. Por outro lado, na maior dose de calcário $\left(5,2 \mathrm{~g} \mathrm{dm}^{-3}\right)$ os teores de $\mathrm{Ca}^{2+}$ e $\mathrm{Mg}^{2+}$ no solo aumentaram, respectivamente, para 5,9 e 3,4 $\mathrm{cmol}_{\mathrm{c}} \mathrm{dm}^{-3}$ e, o CR foi de apenas 14,5 m planta ${ }^{-1}$. Ou seja, com um aumento nos teores de $\mathrm{Ca}^{2+}{\mathrm{e} \mathrm{Mg}^{2+}}^{2}$ no solo, respectivamente de
2,5 e 2,2 $\mathrm{cmol}_{\mathrm{c}} \mathrm{dm}^{-3}$, o $\mathrm{CR}$ reduziu $58,5 \%$. Esse resultado discorda daqueles registrados na literatura, uma vez que é conhecida a importante função do Ca no crescimento radicular (MENGEL e KIRKBY, 1987; MARSCHNER, 1995; EPSTEIN e BLOOM, 2004). Isto, por um lado, comprova a alta tolerância da erva-mate ao $\mathrm{Al}$, visto que os maiores valores de VR e CR (Figura 2D) ocorreram quando o $\mathrm{Al}$ no solo apresentava os maiores teores (Figura 1A). Mas por outro lado, a redução do VR e CR pode ter sido influenciada pela menor disponibilidade de micronutrientes às plantas em decorrência da ação da calagem, verificado pela redução do teor foliar de $\mathrm{Cu}, \mathrm{Zn}$ e principalmente de Mn (Figura 4A, B e C).

Para a erva-mate, dentre as variáveis de crescimento analisadas, a altura e área foliar foram as que mais responderam positivamente ao calcário. Para as variáveis de crescimento relacionadas ao sistema radicular, a ação do calcário foi negativa.

O teor dos elementos no tecido vegetal apresentou comportamento distinto entre os compartimentos, sendo os maiores teores observados na folha, com exceção do $\mathrm{Ca}$ (Figuras $3 \mathrm{e}$ 4). Cada compartimento possui teores de minerais relacionados com suas funções, sendo os maiores teores na folha (BELLOTE e SILVA, 2005), pois é nesta parte da planta que o metabolismo é mais intenso (EPSTEIN e BLOOM, 2004).

Os teores de $\mathrm{N}$ e $\mathrm{K}$ na folha apresentaram comportamento semelhante, sendo o menor teor obtido, respectivamente, de 22,2 e $24,9 \mathrm{~g} \mathrm{~kg}^{-1}$ na dose de 2,8 e 3,9 $\mathrm{g} \mathrm{dm}^{-3}$ (Figura 3A e B). Os maiores teores de $\mathrm{N}$ e $\mathrm{K}$ nas doses extremas $\left(0,0\right.$ e $\left.5,2 \mathrm{~g} \mathrm{dm}^{-3}\right)$, possivelmente, estejam relacionados ao efeito de concentração (EPSTEIN e BLOOM, 2004), principalmente na maior dose de calcário em que o crescimento das plantas foi mais prejudicado.

As doses de calcário não influenciaram o teor de $\mathrm{N}$ no caule e raiz (Figura 3A) e, o teor de $\mathrm{K}$ na raiz (Figura 3B); já o $\mathrm{K}$ no caule teve comportamento linear negativo (Figura 3B). O aumento do teor de $\mathrm{K}$ no solo (Figura 1C) e o menor teor deste na planta (Figura 3B) podem ter ocorrido pela redução do VR e CR (Figura 2D).

O teor máximo de Ca na folha $\left(6,6 \mathrm{~g} \mathrm{~kg}^{-1}\right)$ foi obtido na dose de $4,2 \mathrm{~g} \mathrm{dm}^{-3}$ de calcário, enquanto que para o caule e a raiz, os teores aumentaram linearmente (Figura 3C). Para o $\mathrm{Mg}$, o teor máximo na folha $\left(6,2 \mathrm{~g} \mathrm{~kg}^{-1}\right)$ foi obtido na dose correspondente a $4,8 \mathrm{~g} \mathrm{dm}^{-3}$ de calcário, para a raiz $\left(4,8 \mathrm{~g} \mathrm{~kg}^{-1}\right)$ na dose de $3,4 \mathrm{~g} \mathrm{dm}^{-3}$ e, no caule, o aumento foi linear (Figura 3D). Na dose de calcário 


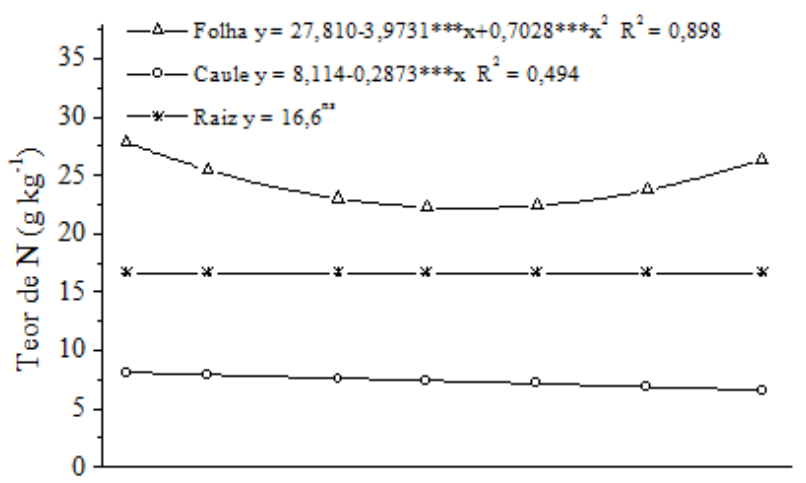

(A)

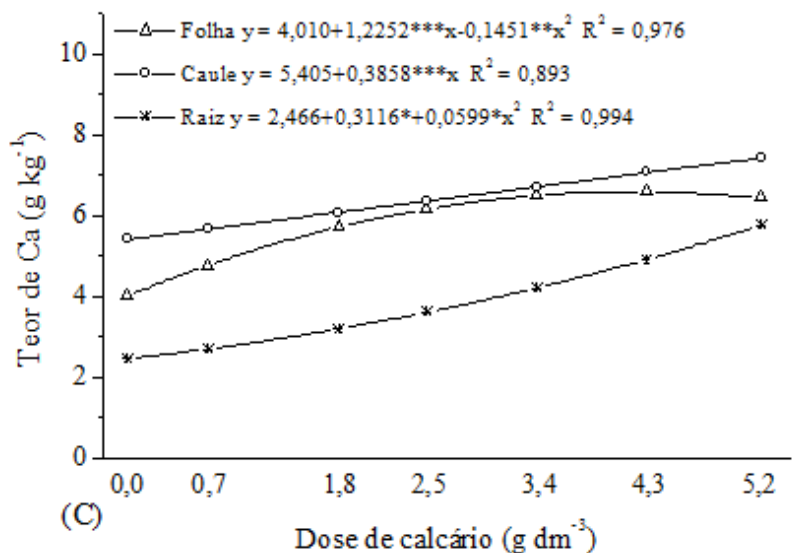

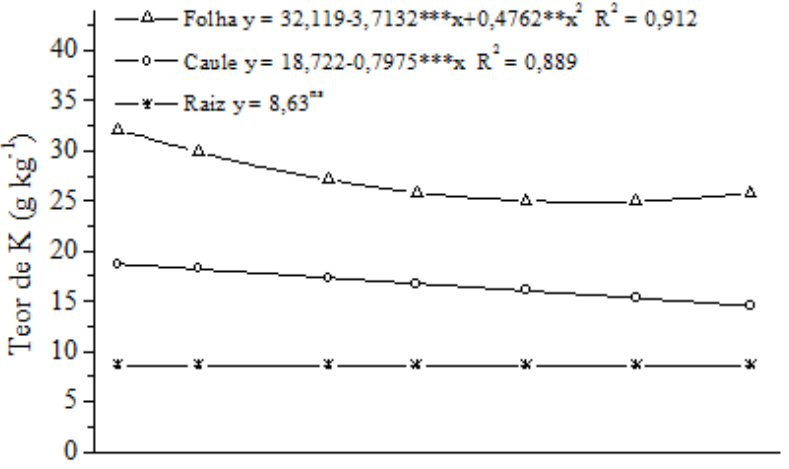

(B)

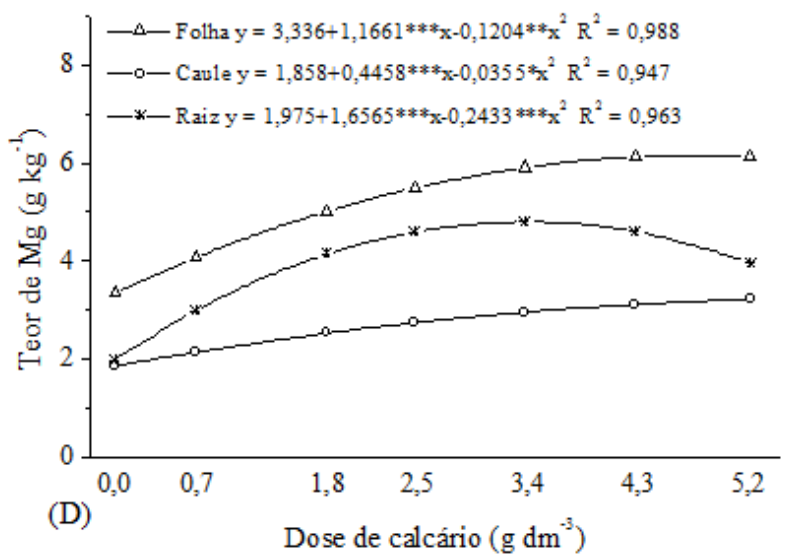

FIGURA 3: Teor de N (A); K (B); Ca (C) e Mg (D) na folha, caule e raiz de plantas jovens de ervamate (Ilex paraguariensis A. St.-Hil.) submetidas a doses de calcário. ns, *,** e ***, não significativo, significativo a 5,1 e $0,1 \%$, respectivamente.

FIGURE 3: Nitrogen (A), $\mathrm{K}(\mathrm{B}), \mathrm{Ca}(\mathrm{C})$ and $\mathrm{Mg}$ (D) content in the leaves, stem and roots of mate (Ilex paraguariensis $\mathrm{A}$. St.-Hil.) seedlings as affected by lime rates. ns, ${ }^{*}, * *$ and $* * *$ non significant and significant to 5, 1 and $0,1 \%$ level, respectively.

para a MET de MSF $\left(1,3 \mathrm{~g} \mathrm{dm}^{-3}\right)$, o teor foliar de Ca foi de $5,4 \mathrm{~g} \mathrm{~kg}^{-1}$ (Figura 3C), indicando que maiores teores não são indicativos de maiores produções. Fato semelhante foi observado com o $\mathrm{Mg}$, para o qual o máximo teor foliar $\left(6,2 \mathrm{~g} \mathrm{~kg}^{-1}\right)$ está acima dos 4,7 $\mathrm{g} \mathrm{kg}^{-1}$ considerados ideal para máxima produção de MSF (Figura 2C). Na dose máxima de calcário constatou-se, principalmente nas folhas jovens, clorose internerval, que seria decorrente da deficiência de micronutrientes, como Zn, Fe e Mn, e ou excesso de Ca. Sintoma semelhante foi relatado por Reissmann et al. (1991) quando testaram, em mudas de erva-mate, calagem para atingir $80 \mathrm{e}$ $100 \%$ de saturação por bases.

De maneira geral, os teores foliares de micronutrientes e de $\mathrm{Al}$ diminuíram com o aumento das doses de calcário (Figura 4A, B, C, D e E). O teor de $\mathrm{Cu}$ na folha e na raiz reduziu linearmente (Figura
4A). No caule, o teor de $\mathrm{Cu}$ reduziu até a dose de $1,7 \mathrm{~g} \mathrm{dm}^{-3}$ de calcário $\left(6,9 \mathrm{mg} \mathrm{kg}^{-1}\right)$ e, na maior dose, obteve o teor máximo $\left(12,1 \mathrm{mg} \mathrm{kg}^{-1}\right)$. Assim como para os demais micronutrientes analisados, o calcário também reduziu o teor foliar de Fe (Figura 4B), tendo na dose de $2,5 \mathrm{~g} \mathrm{dm}^{-3}$ teor mínimo de $45,9 \mathrm{mg} \mathrm{kg}^{-1}$. Já na raiz, o teor de $\mathrm{Fe}$ aumentou com a dose de calcário, atingindo o máximo de $270,9 \mathrm{mg} \mathrm{kg}^{-1}$, na dose de $2,9 \mathrm{~g} \mathrm{dm}^{-3}$. Os teores de $\mathrm{Zn}$ na folha e no caule tiveram o mesmo comportamento, com ponto de mínimo, respectivamente, nas doses de 4,9 e 4,0 $\mathrm{g} \mathrm{dm}^{-3}$. Na raiz, o teor de $\mathrm{Zn}$ reduziu linearmente com as doses de calcário (Figura 4C). Para o Mn, o teor máximo na raiz foi de $26,0 \mathrm{mg} \mathrm{kg}^{-1} \mathrm{e}$, no caule o teor mínimo de 6,7 $\mathrm{mg} \mathrm{kg}^{-1}$, ambos na dose de 4,7 $\mathrm{g} \mathrm{dm}^{-3}$ de calcário (Figura 4D). Na folha, o teor deste reduziu com o aumento das doses, tendo a maior magnitude 

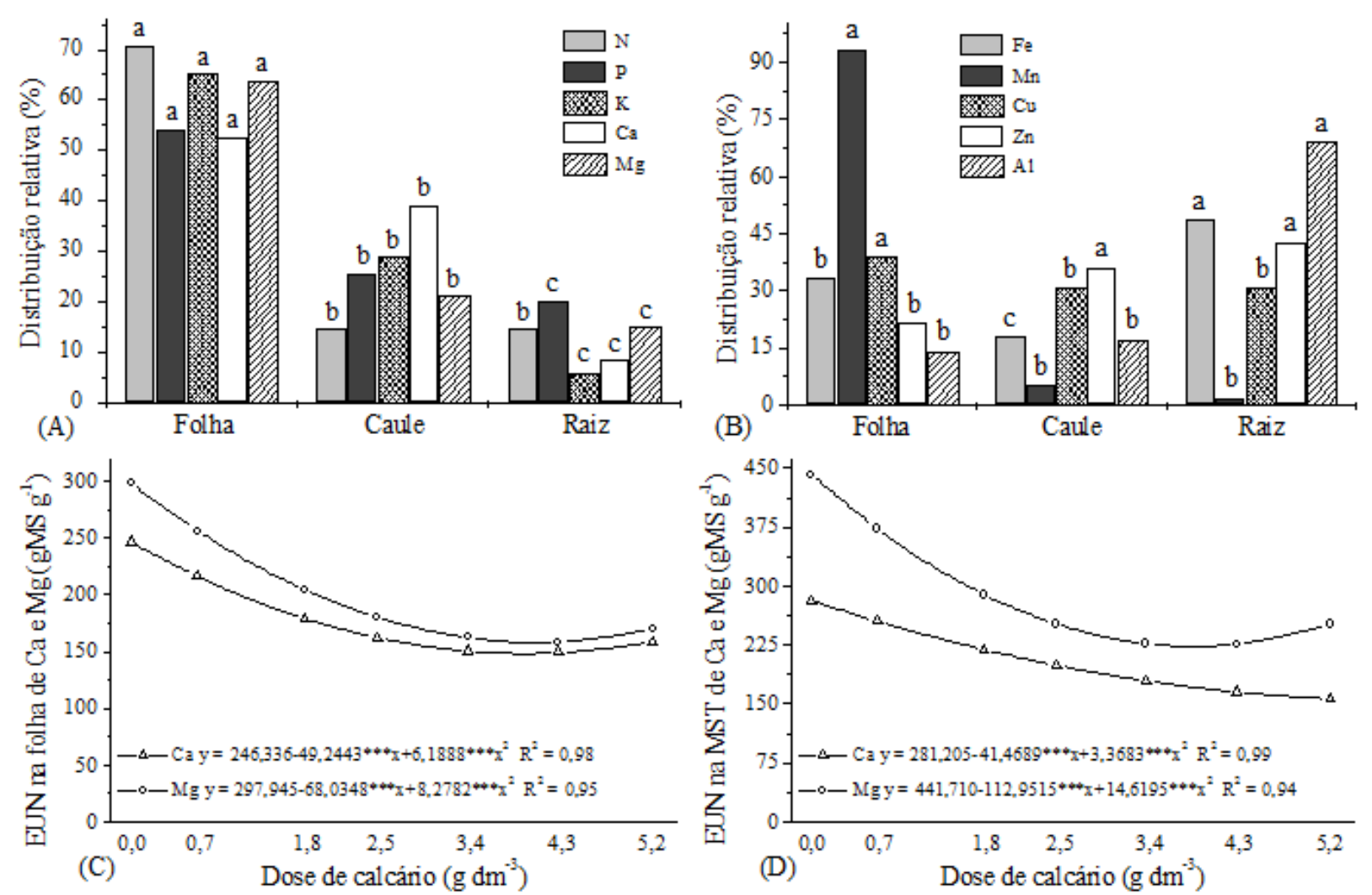

FIGURA 4: Distribuição relativa na folha, caule e raiz de N, P, K, Ca e Mg (A) de Fe, Mn, Cu, Zn e Al (B) e eficiência de utilização de nutrientes (EUN) de Ca e Mg na matéria seca da folha (C) e total (MST) (D) em plantas jovens de erva-mate (Ilex paraguariensis A. St.-Hil.) submetidas a doses de calcário. Médias entre compartimentos seguidas de pelo menos uma mesma letra não diferem estatisticamente entre si pelo teste Tukey $(\mathrm{p}<0,05)$. *** significativo a $0,1 \%$.

FIGURE 4: Nitrogen, $\mathrm{P}, \mathrm{K}, \mathrm{Ca}$ and $\mathrm{Mg}(\mathrm{A})$ and $\mathrm{Fe}, \mathrm{Mn}, \mathrm{Cu}, \mathrm{Zn}$ and $\mathrm{Al}$ relative content (B), $\mathrm{Ca}$ and $\mathrm{Mg}$ use efficiencyfor leaf (C) and total biomass (D) of mate (Ilex paraguariensis A. St.-Hil.) seedlings as affected by lime rates. Different letters indicate differences among seedling compartments by the Tukey test at the $5 \%$ level. *** significant to $0,1 \%$.

de redução entre os micronutrientes analisados, com teores médios variando de 728,6 a $183,1 \mathrm{mg} \mathrm{kg}^{-1}$. $\mathrm{O}$ Al na folha e na raiz apresentou comportamento semelhante, com redução do teor com o aumento das doses de calcário, tendo teores mínimos, respectivamente, de 70,3 e 1353,6 $\mathrm{mg} \mathrm{kg}^{-1}$ nas doses de 4,3 e 4,1 $\mathrm{g} \mathrm{dm}^{-3}$ de calcário. No caule o teor máximo de $\mathrm{Al}\left(170,3 \mathrm{mg} \mathrm{kg}^{-1}\right)$ ocorreu na dose de $2,0 \mathrm{~g} \mathrm{dm}^{-3}$ (Figura 4E).

A grande diferença entre o teor de Mn foliar e radicular chama a atenção. Diante disso, observouse alta correlação entre o teor foliar de $\mathrm{Al}$ e a relação do teor de $\mathrm{Mn}$ foliar e radicular $(\mathrm{MnF} / \mathrm{MnR})$ e entre o teor foliar de $\mathrm{Al}$ com o teor foliar de Mn (Figura 4F).

A redução do teor da maioria dos micronutrientes e Al na planta, possivelmente está relacionada à diminuição dos teores disponíveis destes no solo, pois, dentre os principais fatores que controlam a atividade do $\mathrm{Cu}, \mathrm{Mn}, \mathrm{Zn}, \mathrm{Fe}$ e $\mathrm{Al}$ no solo, destaca-se o $\mathrm{pH}$ (LINDSAY, 2001), que quanto maior, menor será a disponibilidade desses elementos para as plantas (SOUSA et al., 2007).

Nota-se que a erva-mate apresentou maior teor de $\mathrm{Cu}, \mathrm{Zn}, \mathrm{Fe}$ e $\mathrm{Al}$ na raiz e, para o $\mathrm{Mn}$, isso ocorreu na folha. Deve-se ressaltar que normalmente, a disponibilidade de micronutrientes nas plantas é afetada por valores de $\mathrm{pH}$ do solo mais elevados do que os atingidos neste trabalho. Apesar de a calagem ter elevado apenas 0,9 unidade de $\mathrm{pH}$, a mudança no teor desses elementos nas plantas foi evidente. 
O alto valor da relação entre o teor de $\mathrm{Mn}$ foliar e radicular (MnF/MnR) pode estar relacionado a mecanismos da planta em minimizar os possíveis efeitos negativos do alto teor foliar de Al comumente verificado na erva-mate. Blair e Thaylor (1997) observaram diminuição na acumulação de A1 nas raízes e brotos de Triticum aestivum pelo Mn. Para a erva-mate, mesmo que a calagem tenha atuado na redução da disponibilidade de $\mathrm{Mn}$ e Al para as plantas, a alta correlação entre o teor foliar de $\mathrm{Al}$ e $\mathrm{MnF} / \mathrm{MnR}$ e o teor foliar de $\mathrm{Al}$ e Mn (Figura 4F) merece ser investigada.

A avaliação do melhor estado nutricional de culturas por análise de tecido normalmente é realizada na faixa do nível crítico, que ocorre próximo da produção máxima (EPSTEIN e BLOOM, 2004). Considerando que o produto colhido da erva-mate é composto por folhas e galhos finos, neste trabalho, as variáveis que melhor representam esses componentes são a MSF e MSC. Na dose de calcário de MET para a MSF e MSC (1,4 $\left.\mathrm{g} \mathrm{dm}^{-3}\right)$ o teor foliar de N, K, Ca e Mg estão acima e o do P abaixo (Tabela 2) dos teores encontrados por Reissmann et al. (1999) em mudas de um ano de idade e, de plantas com oito meses após plantio a campo submetidas à calagem (REISSMANN et al., 1997).

$\mathrm{O}$ teor foliar de micronutrientes e $\mathrm{Al}$ (Tabela 2) estão abaixo da média, tanto para mudas de um ano como para plantios de dois anos de idade (REISSMANN et al., 1999). Assim, outra hipótese para a redução do crescimento da erva-mate nas maiores doses de calcário pode não ser decorrente apenas do maior teor de $\mathrm{Ca}$ e $\mathrm{Mg}$ no solo, mas também da redução da disponibilidade da maioria dos micronutrientes, induzida pela calagem.

A maior distribuição relativa dos macronutrientes foi observada nas folhas e, as raízes, obtiveram os menores valores de $\mathrm{P}, \mathrm{K}, \mathrm{Ca}$ e $\mathrm{Mg}$, com exceção do N que foi igual ao caule (Figura 5A). Para os micronutrientes, o comportamento foi variável. $\mathrm{O}$ maior valor de $\mathrm{Mn}$ e $\mathrm{Cu}$ foi obtido na folha, o de $\mathrm{Fe}$ e $\mathrm{Al}$ na raiz e o de $\mathrm{Zn}$ no caule e raiz (Figura 5B).

Observa-se maior EUN para $\mathrm{Ca}$ e $\mathrm{Mg}$ nas menores doses de calcário, tanto para a MSF (Figura 5C) como para a MST (Figura 5D). Na folha a EUN mínima de $\mathrm{Ca}$ e $\mathrm{Mg}$ foi respectivamente de 148,4 e 158,2 $\mathrm{gMS} \mathrm{g}^{-1}$ nas doses de 4,0 e $4,1 \mathrm{~g} \mathrm{dm}^{-3}$. Para a MST a EUN mínima de $\mathrm{Ca}$ e $\mathrm{Mg}$ foi, respectivamente, de 156,6 e $223,5 \mathrm{gMS} \mathrm{g}^{-1}$. $\mathrm{Na}$ testemunha, tanto na folha quanto na planta total, ocorreu a maior diferença de EUN entre o $\mathrm{Ca}$ e $\mathrm{Mg}$, com superioridade do $\mathrm{Mg}$. Porém, principalmente na folha, á medida que as doses de calcário aumentaram essa diferença diminuiu, demonstrando que a erva-mate, quando submetida à aplicação de calcário dolomítico está mais sujeita a maiores aumentos do teor de $\mathrm{Mg}$ no tecido vegetal, quando comparado aos de Ca. De acordo com Barros et al. (1986) a EUN para um determinado nutriente pode variar à medida que sua disponibilidade no solo seja alterada. Em geral, a EUN pela planta aumenta com a redução de sua disponibilidade no solo, comportamento verificado nesse estudo.

TABELA 2: Teor de macronutrientes, micronutrientes e Al na folha, caule e raiz na dose de MET para a MSF e MSC de plantas jovens de erva-mate (Ilex paraguariensis A. St.-Hil.) submetidas a doses de calcário.

TABLE 2: Contents of macro and micronutrients and Al in leaves, stem and roots of mate tea (Ilex paraguariensis A. St.-Hil.) seedlings at the liming maximum efficiency for leaf and stem production as affected by lime rates.

\begin{tabular}{|c|c|c|c|c|c|c|c|c|c|c|}
\hline \multirow{2}{*}{$\begin{array}{l}\text { Parte da } \\
\text { planta }\end{array}$} & \multicolumn{5}{|c|}{ Teor $^{11}$ de macronutrientes } & \multicolumn{5}{|c|}{ Teor $^{11}$ de micronutrientes e $\mathrm{Al}$} \\
\hline & $\mathrm{N}$ & $\mathrm{P}$ & K & $\mathrm{Ca}$ & $\mathrm{Mg}$ & $\mathrm{Cu}$ & $\mathrm{Fe}$ & $\mathrm{Mn}$ & $\mathrm{Zn}$ & $\mathrm{Al}$ \\
\hline & \multicolumn{5}{|c|}{ - - - - - - - - $\mathrm{g} \mathrm{kg}^{-1} \ldots$} & - & $-\ldots$ & $\mathrm{mg} \mathrm{kg}$ & $-\ldots$ & $--{ }_{-1}$ \\
\hline Folha & 23,6 & 0,9 & 27,9 & 5,4 & 4,7 & 6,9 & 48,0 & 581,7 & 12,1 & 126,5 \\
\hline Caule & 7,7 & 0,6 & 17,6 & 5,9 & 2,4 & 6,7 & 50,3 & 63,1 & 35,2 & 168,5 \\
\hline Raiz & 16,6 & 1,1 & 8,6 & 3,0 & 3,8 & 17,2 & 264,3 & 25,5 & 73,3 & 1733,0 \\
\hline
\end{tabular}

Em que: ${ }^{1}=$ teores obtidos na dose de calcário $\left(1,4 \mathrm{~g} \mathrm{dm}^{-3}\right)$ em que ocorreu o máximo crescimento de matéria seca de folha e caule. 


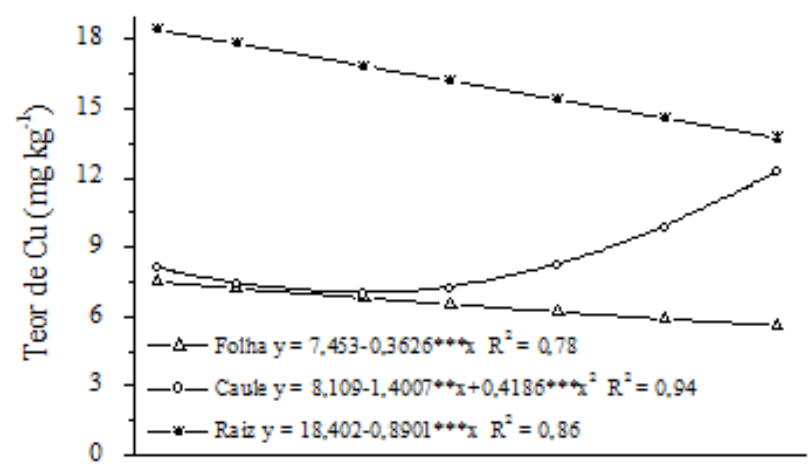

(A)

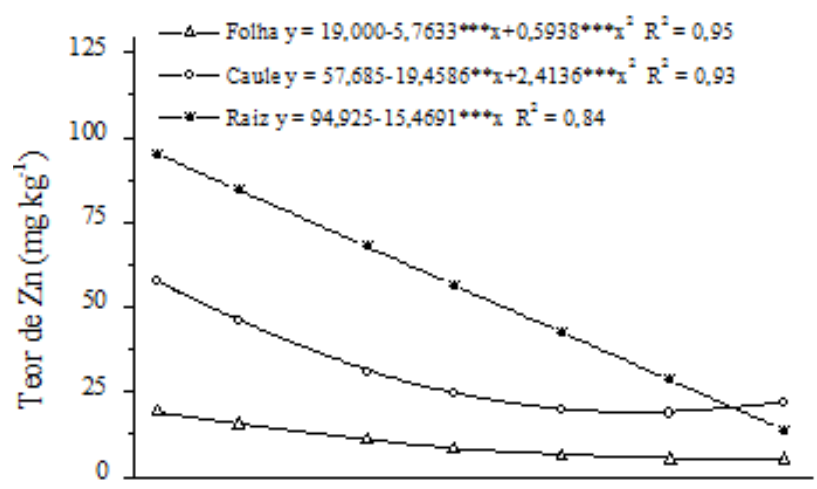

(C)

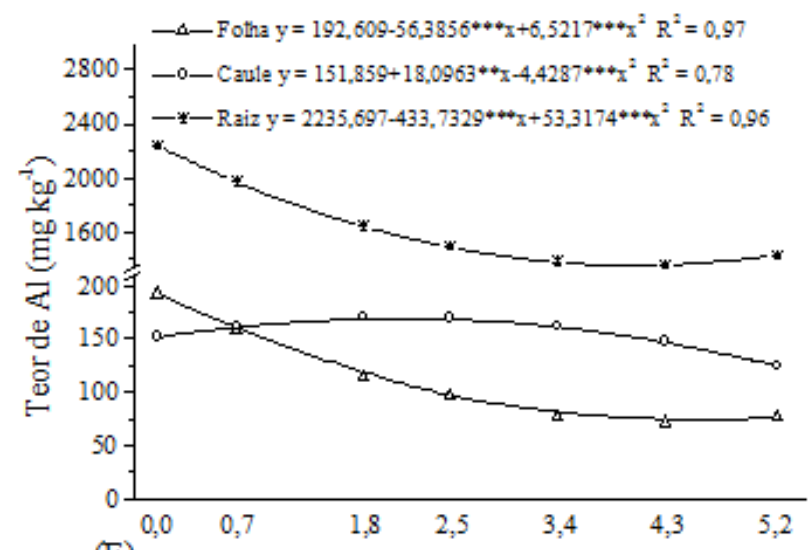

(E)

Dose de calcário $\left(\mathrm{g} \mathrm{dm}^{-3}\right)$

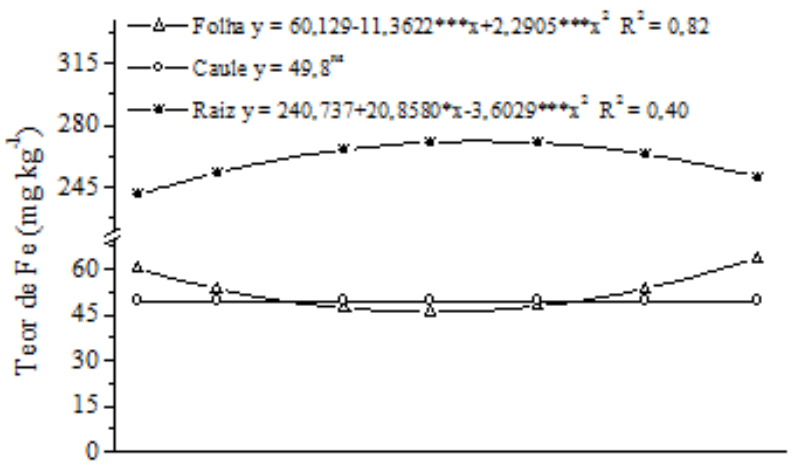

(B)
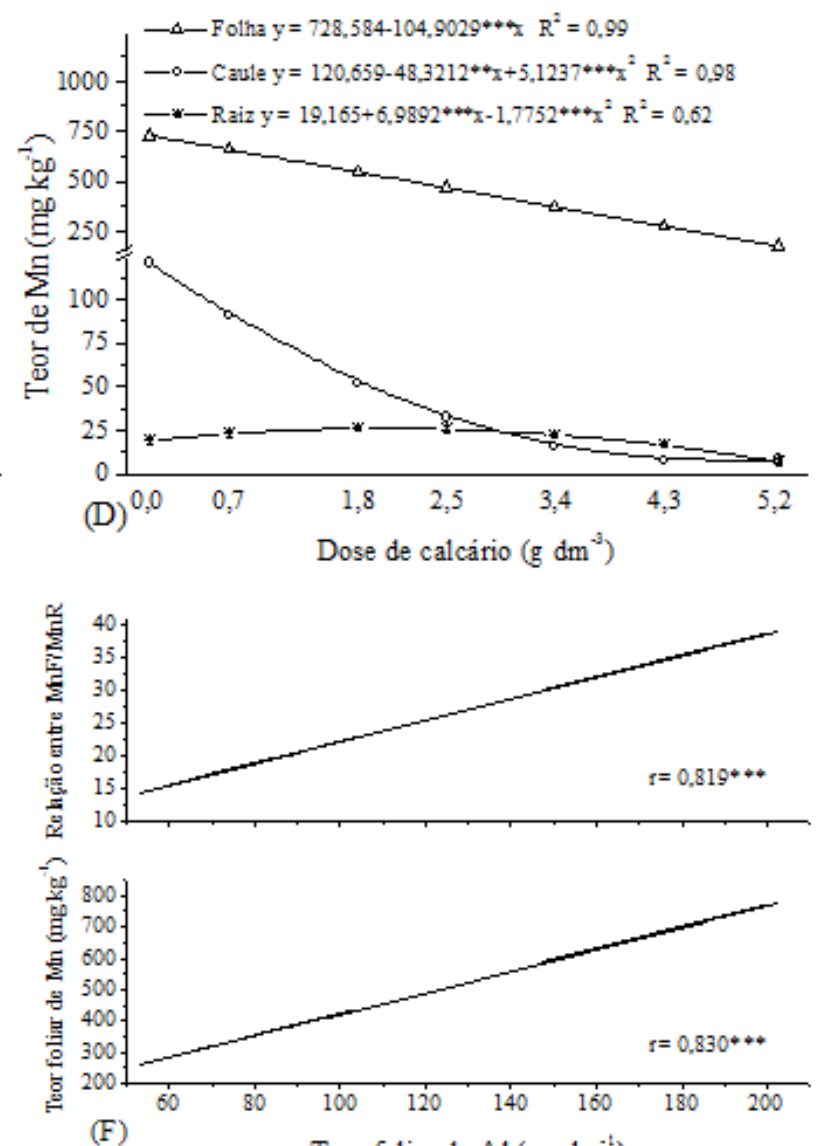

(F) Teor foliar de $\mathrm{Al}\left(\mathrm{mg} \mathrm{kg}^{-\mathrm{t}}\right)$

FIGURA 5: Teor de $\mathrm{Cu}$ (A); Fe (B); Zn (C); $\mathrm{Mn}$ (D); $\mathrm{Al}$ (E) na folha, caule e raiz, e correlação entre teor foliar de Al e relação do $\mathrm{Mn}$ na folha e $\mathrm{Mn}$ na raiz e entre teor foliar de Al e $\mathrm{Mn}$ (F) em plantas jovens de erva-mate (Ilex paraguariensis A. St.-Hil.) submetidas a doses de calcário. ns, *, ** e ***, não significativo, significativo a 5,1 e $0,1 \%$, respectivamente.

FIGURE 5: Copper (A), Fe (B), Zn (C), Mn (D), Al (E) content of leaves, stem and roots, and correlation between foliar $\mathrm{Al}$ and $\mathrm{Mn}$ in the ratio of $\mathrm{Mn}$ in leaf and root and between foliar $\mathrm{Mn}$ and $\mathrm{Al}(\mathrm{F})$ of mate (Ilex paraguariensis A. St.-Hil.) seedlings as affected by lime rates. ns, ${ }^{*}, * *$ and *** non significant and significant to 5,1 and 0,1\% level, respectively. 


\section{CONCLUSÕES}

A calagem afetou o crescimento da parte aérea, mas não das raízes, da erva-mate.

Doses de calcário que elevam os teores de $\mathrm{Ca}^{2+} \mathrm{e} \mathrm{Mg}^{2+}$ no solo a valores iguais ou superiores a 6,0 e $3,4 \mathrm{cmol}_{\mathrm{c}} \mathrm{dm}^{-3}$, respectivamente, reduzem fortemente o crescimento de plantas jovens de erva-mate e induzem sintomas de deficiência de micronutrientes, principalmente de $\mathrm{Zn}, \mathrm{Mn}$ e Fe e ou sintomas de toxidez de $\mathrm{Ca}$.

A erva-mate é pouco responsiva à calagem e tolerante ao $\mathrm{Al}$ e à aplicação de calcário deve visar ao suprimento de $\mathrm{Ca}$ e $\mathrm{Mg}$ para as plantas e não à correção da acidez do solo.

\section{AGRADECIMENTOS}

À empresa Baldo S.A. de São Mateus do Sul-PR, à UFPR e à Embrapa Florestas de Colombo$\mathrm{PR}$, que juntas, possibilitaram a realização deste trabalho.

\section{REFERÊNCIAS BIBLIOGRÁFICAS}

BARROS, N. F. et al. Classificação nutricional de sítios florestais - Descrição de uma metodologia. Revista Árvore, Viçosa, v. 10, n. 2, p. 112-120, jan./jun.1986.

BELlOTE, A. F. J.; SILVA, H. D. Técnicas de amostragem e avaliações nutricionais em plantios de Eucalyptus spp. In: GONÇALVES, J. L. M.; BENEDETTI, V. Nutrição e fertilização florestal. Piracicaba: IPEF, 2005. p. 105-133.

BENEDETTI, E. L. et al. Calagem e adubação no crescimento de espinheira-santa [Maytenus ilicifolia (Schrad.) Planch.] em casa de vegetação. Revista Brasileira de Plantas Medicinais, Botucatu, v. 11, n. 3, p. 269-276, 2009.

BISSANI, C. A. et al. Solos ácidos e solos afetados por sais. In: MEURER, E. J. Fundamentos de química do solo. 2. ed., Porto Alegre: Gênesis, 2004. p. 181-205.

BLAIR, L. M.; TAYLOR, G. J. The nature of interaction between aluminum and manganese ongrowth and metal accumulation in Triticum aestivum. Environmental and Experimental Botany, v. 37, n. 1, p. 25-37, 1997.

BREMNER, J. M. Nitrogen total. In: SPARKS, D.L. Methods of soil analysis. Part 3. Madison: America Societyof Agronomy, 1996. p. 1085-1121.

CARVALHO, P. H. R. Espécies arbóreas brasileiras. Brasília: Embrapa Informação tecnológica, 2003. 1039 p.

DEDECEK, R. A.; RODIGHERI, H. R. Sistemas de preparo do solo em cultivos anuais intercalados em erva-mate. Boletim de Pesquisa Florestal, Colombo, n. 38, p. 77-88, jan./jun. 1999.

EMBRAPA. Manual de métodos de análise de solo. 2. ed., Rio de Janeiro: EMBRAPA, 1997. $212 \mathrm{p}$.

EPSTEIN, E.; BLOOM, A. J. Nutrição mineral de plantas: princípios e perspectivas. 2. ed. Londrina: Planta, 2004. 403 p.

FERREIRA, D. F. Sisvar: um programa para análises e ensino de estatística. Revista Científica Symposium, Lavras, v. 6, n. 2, p. 36-41, jul./dez. 2008.

FURTINI NETO, A. E. et al. Acidez do solo, crescimento e nutrição mineral de algumas espécies arbóreas, na fase de muda. Cerne, Lavras, v. 5, n. 2, p. 01-12, 1999a.

FURTINI NETO, A. E. et al. Liming effects on growth of native woody species from Brazilian savannah. Pesquisa Agropecuária Brasileira, Brasília, v. 34, n. 5, p. 829-837, maio. 1999b.

GAIAD, S. Alteração da rizosfera e seus reflexos na biomatéria, na composição química e na fotossíntese de erva-mate decorrentes do uso de diferentes fontes de nitrogênio. $2003.132 \mathrm{f}$. Curitiba. Tese (Doutorado em Engenharia Florestal) - Universidade Federal do Paraná, Curitiba, 2003.

LINDSAY, W. L. Chemical equilibria in soils. New Jersey: Blackburn, 2001. 449 p.

MA, J. F.et al. Aluminium tolerance in plants and the complexing role of organic acids. Trends Plant Science, v. 6, n. 6, p. 1360-1385, June. 2001.

MACCARI, JR. A.; MAZUCHOWSKI, J. Z. Produtos alternativos e desenvolvimento da tecnologia industrial na cadeia produtiva da erva-mate. Curitiba: Câmara Setorial da Cadeia Produtiva da Erva-Mate Paraná MCT/CNPq/ PROJETO PADCT Erva-Mate, 2000. 176 p.

MARSCHNER, $H$. Mineral nutrition of higher plants. London: Academic Press, 1995. $889 \mathrm{p}$.

MARTINS, A. P. L.; REISSMANN, C. B. Material vegetal $\mathrm{e}$ as rotinas laboratoriais nos procedimentos químico-analíticos. Scientia Agraria, Curitiba, v. 8, n. 1, p. 1-17, jan./mar. 2007.

MELLO, J. V. de.; PEREZ, D. V. Equilíbrio químico das reações do solo. In: MELO, V. F.; ALLEONI, L. R. F. Química e mineralogia do solo. Viçosa: Sociedade Brasileira de Ciência do 
Solo, v. 1, 2009. p. 151-249.

MENGEL, K.; KIRKBY, E. A. Principles of plant nutrition. $4^{\text {th }}$ ed. Bern: International Potash Institute, 1987, $687 \mathrm{p}$.

MEURER, E. J. et al. Fenômenos de sorção em solos. In.: MEURER, E. J. Fundamentos de química do solo. 2. ed. Porto Alegre: Genesis, 2004. p. 131-179. REISSMANN, C. B. et al. Chemical composition of Ilex paraguariensis St. Hil. Under different management conditions in seven localities of Paraná State. Brazilian Archives of Biology and Technology, Curitiba, v. 42, n. 2, p. 187-194, 1999. REISSMANN, C. B. et al. Production and foliar $\mathrm{N}, \mathrm{P}, \mathrm{K}, \mathrm{Ca}$ and $\mathrm{Mg}$ levels in erva-mate (Ilex paraguariensis St. Hil.), related to increasing base saturation levels. Arquivos Biologia e Tecnologia, Curitiba, v. 40, n. 1, p. 241-249, mar. 1997.

REISSMANN, C. B. et al. Suscetibilidade da ervamate à clorose induzida pela calagem. Revista do setor de Ciências Agrárias, Curitiba, v. 11, n.
1-2, p. 273-278, 1991.

REISSMANN, C. B.; CARNEIRO, C. Crescimento e composição química de erva-mate (Ilex paraguariensis St. Hil.), transcorridos oito anos de calagem. Floresta, v. 34, n. 3, p. 381-386, set./dez. 2004.

SBCS - Sociedade Brasileira de Ciência do Solo. Manual de adubação e calagem para os Estados do Rio Grande do Sul e de Santa Catarina. 10. ed. Porto Alegre: Comissão de Química e Fertilidade do Solo, 2004. 400 p.

SOUSA, D. M. G. et al. Acidez do solo e sua correção. In: NOVAIS, R. F. et al. Fertilidade do solo. Viçosa: Sociedade Brasileira de Ciência do Solo, 2007. p. 205-274.

ZAMPIER,A.C.Avaliação dos níveis de nutrientes, cafeína e taninos após adubação mineral e orgânica e sua relação com a produtividade na erva-mate (Ilex paraguariensis St. Hil). 2001. 94 f. Dissertação (Mestrado em Engenharia Florestal) - Universidade Federal do Paraná, Curitiba, 2001. 